\title{
A HYBRID MODEL FOR DECISION-MAKING IN THE INFORMATION AND COMMUNICATIONS TECHNOLOGY SECTOR
}

\author{
Andrés CID-LÓPEZa , Miguel J. HORNOS ${ }^{\mathrm{a}}$, Ramón Alberto CARRASCO ${ }^{\mathrm{b}}$, \\ Enrique HERRERA-VIEDMA ${ }^{\mathrm{c}, \mathrm{d}}$ \\ ${ }^{a}$ Department of Software Engineering, University of Granada, 18071 Granada, Spain \\ ${ }^{b}$ Department of Marketing and Market Research, Complutense University of Madrid, \\ 28015 Madrid, Spain \\ ${ }^{c}$ Department of Computer Science and Artificial Intelligence, University of Granada, \\ 18071 Granada, Spain \\ ${ }^{d}$ Department of Electrical and Computer Engineering, King Abdulaziz University, \\ 21589 Jeddah, Saudi Arabia
}

Received 10 March 2015; accepted 17 May 2015

\begin{abstract}
The majority of businesses in the Information and Communications Technology (ICT) sector face decision-making problems on a daily basis. Most of these problems are based on contexts of uncertainty, where decisions are founded on qualitative information which may be imprecise or perception-based. In these cases, the information which is expressed by experts and users of evaluated services can be treated using processes of computing with words $(\mathrm{CW})$. In this paper, we present a hybrid decision-making model especially designed for the ICT sector whereby the experts have the support of an intelligent system which provides information about the opinions of users related to those problems which are to be analysed. These opinions are obtained by using different mechanisms and techniques when users conduct business with the service provider. In addition, we employ a procedure for obtaining consensus between experts which enriches and strengthens the decision-making process.
\end{abstract}

Keywords: Information and Communications Technology, multicriteria decision-making, 2-tuple linguistic computational model, computing with words.

JEL Classification: D81, D83, M15, L86, L96.

\section{Introduction}

Economic growth in a large number of countries is linked to the development and use of ICTs. This link between ICTs and economic development is noted in several works (e.g. Pérez 2004; Katz 2009; Peres, Hilbert 2009; Naser, Concha 2014), where it is suggested that

Corresponding authors Andrés Cid-López, Miguel J. Hornos

E-mails: andrescid@ugr.es; mhornos@ugr.es 
the use and spread of information technology to other sectors could result in a sustained increase in the potential average growth rate in the economy. Taking into account the importance of this sector for a country's economy, this work aims to provide an additional tool to facilitate decision-making in ICT-related sectors.

The use of experts in decision-making is a common practice; however, there are a number of limitations involved. Among these limitations, we could mention the following ones: the impossibility of having them permanently, there are time restrictions involved in decision-making, the level of knowledge or experience of the experts may not be sufficient, and the level of responsibility in relation to the assigned tasks may vary from one expert to another.

To mitigate these limitations, our proposal is based on the utilisation of all available sources of information. Here, we are referring to the effective use that can be made of experience expressed verbally by those who are directly involved (available experts), as well as the anonymous opinions provided by external customers (clients) and internal users (staff). All of this information is collected by different means and mechanisms of contact, including, for example, surveys conducted with clients or users of the services of a given company. The aim here is to find out the expectations and perceptions of users who make up the portfolio of clients.

It is important to highlight that the above-mentioned data-collection procedures and mechanisms may or may not take place on a face-to-face basis. This means that it is not entirely necessary to have the physical presence of users in order to be able to investigate, to assess or to know their opinions regarding diverse topics of interest. As indicated, the aim of these information search mechanisms is to obtain additional information not only from external users (those who are not directly linked to the service provider), but also from internal users (those who have a direct link to the service provider). In the latter case, since internal users form part of the business conglomerate, they usually provide a richer source of information because they play two roles: on the one hand, they are clients of the service; on the other, they are part of the business.

Our proposal does not aim to create a substitute method for mature and proven technologies; instead, we provide a technological tool which is complementary to data analysis. In addition, the opinions collected are processed using fuzzy logic and CW, which ensures that there is no loss of information, since qualitative data provided are treated by using labels expressed in natural language, without having to transform it into numerical values, as is necessary in other methods.

This proposal arises as a result of the previous analyses of a series of studies dealing with multicriteria decision-making (MCDM). Among these works, we would highlight the ones authored by: Gal et al. (1999), where the main decision-making models are explained; Cabrerizo et al. (2009), who explain how fuzzy linguistic information is modelled; Oh et al. (2009) and $\mathrm{Hu}$ et al. (2014), who have developed decision-making models in the telecommunications sector; Tseng (2011), Carrasco et al. (2012) and Park and Jeong (2013), where models of quality of service are detailed; Pérez et al. (2010), who have developed a mobile decision support for dynamic group decision-making problems; Carrasco et al. (2011), where a decision-making model is applied to education; Zavadskas and Turskis (2011), who 
present an overview on MCDM methods applied in economics; Keršulienè and Turskis (2011), where a model for architect selection is presented; and Elbarkouky et al. (2012), who provide a decision-making model employed in services and infrastructure.

Based on this previous analysis work, and taking into account other works that use a combination of some existing models (Porcel et al. 2012; Kabak, Dağdeviren 2014), we present the Hybrid Model for Decision-Making (HMDM) in the ICT sector. This name has been chosen because it involves human experts, on the one hand, and, on the other, an intelligent information system that plays the role of a virtual expert, since it processes, accumulates and presents the opinions expressed by the users. Once these opinions are collected, a consensus is reached according to previously stipulated criteria.

The rest of this article is structured in four further sections. In Section 1, the necessary preliminary concepts and theoretical bases are introduced. In Section 2, the proposed model (HMDM) is described. In Section 3, this model is applied to a practical case in the ICT sector. In Section 4, the results obtained are analysed and discussed. Finally, the conclusions are presented along with possible future research.

\section{Material and methods}

In this section, we will provide a brief revision of the main concepts and theoretical underpinnings used for our proposal.

\subsection{Fuzzy linguistic approach}

We are generally accustomed to working with quantitative information, which is expressed through precise numerical values. However, in many real-life problems, these values are not available; instead, we depend on perceptions or imprecise knowledge. According to Zadeh (1975), it is possible to use a fuzzy linguistic approach to represent this knowledge using linguistic variables instead of numerical values.

Definition 1. (Linguistic variable): A linguistic variable is one which is characterized by a quintuple $(V, T(V), X, G, M)$, where:

- $V$ is the name of the variable;

- $T(V)$ is the set of terms of $V$, where each value is a fuzzy linguistic label (represented as $v$ ) which varies throughout the universe of the discourse;

- $X$ is the universe of the discourse;

- $G$ is a syntactic rule for generating the terms of $T(V)$, in other words, the linguistic labels of $V$; and

- $M$ represents a semantic rule for associating each linguistic value $v$ with its corresponding meaning $M(v)$, which is a subset of $X$.

Taking into account the above definition, it is necessary to carefully choose the linguistic descriptors for the group of linguistic terms and their semantics, which are given by means of fuzzy numbers. 
According to Bonissone (1980), one way of presenting a fuzzy number is by using a parametric representation of its membership functions. A fuzzy set $A$ in a universe of discourse $X$ is defined as the following set of pairs:

$$
A=\left\{\left(x, \mu_{A}(x)\right) ; x \in X\right\} .
$$

Here $\mu_{A}: X \rightarrow[0,1]$ is a membership function of the fuzzy set $A$; thus, $\mu_{A}(x)$, often written as $A(x)$, gives us the degree of membership of the value $x \in X$ to the fuzzy set $A$. A membership function links elements $x$ of one discourse domain $X$ with elements of the interval $[0,1]$, which means that the closer $A(x)$ is to value 1 , the greater the membership is of object $x$ to the set $A$. This can be carried out in different ways. In our case, we have chosen five linguistic terms that are linearly and uniformly distributed, using a triangular membership function, as shown in Figure 1. The labels used are in the set $S=\left\{s_{0}, s_{1}, s_{2}, s_{3}, s_{4}\right\}$.

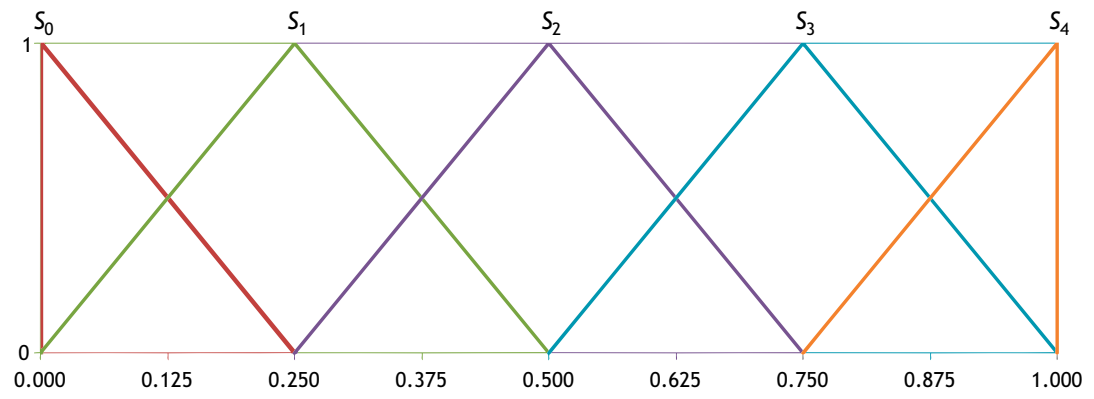

Fig. 1. Triangular linguistic labels

The definition of the semantics of the labels of an ordered set must fulfil the properties defined by the following operators:

- Negation operator: $\operatorname{Neg}\left(s_{i}\right)=s_{j}, j=g-i(g+1$ is the cardinality of $S)$;

- Maximization operator: $\max \left(s_{i}, s_{j}\right)=s_{i}$, if $s_{i} \geq s_{j}$;

- Minimization operator: $\min \left(s_{i}, s_{j}\right)=s_{i}$, if $s_{i} \leq s_{j}$.

\subsection{Linguistic decision-making}

The basic problem of Linguistic Decision-Making (LDM) consists in choosing the best possible solution from a number of alternatives $A=\left\{A_{1}, \ldots, A_{n}\right\}$. In order to arrive at this result, a group of experts $E=\left\{e_{1}, \ldots, e_{m}\right\}$ express their assessments $x_{i}^{j}, \forall i \in\{1, \ldots, n\}$, $\forall j \in\{1, \ldots, m\}$, using a set of linguistic terms $S=\left\{s_{0}, \ldots, s_{g}\right\}$. The values $x_{i}^{j} \in S$ are fuzzy sets defined by a membership function in $[0,1]$.

A diagram of the steps to be taken in solving an LDM problem is presented in Figure 2 and, as can be observed, the process has several phases. The Aggregation phase (see right Figure 2, which shows the steps to be taken within the Selection of Alternatives phase) is where the collective assessments corresponding to each alternative are obtained. In the Exploitation phase, we obtain the best solution from the set of possible alternatives $A$ to 


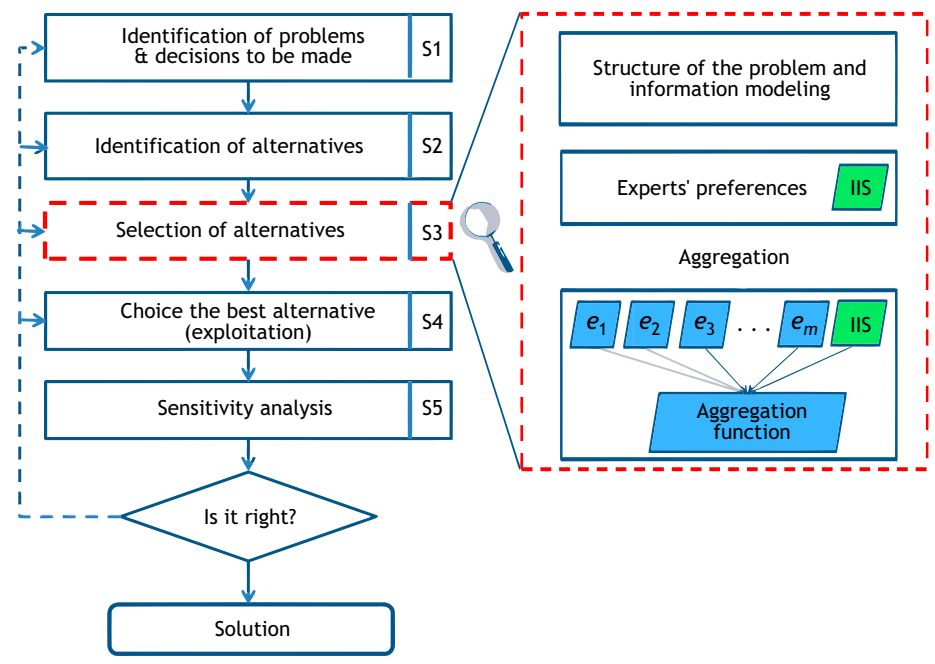

Fig. 2. Scheme of our decision-making process (left). Tasks to be carried out within the phase called Selection of Alternatives (right)

resolve the problem. At the end of the Sensitivity Analysis phase (step S5 in Fig. 2), the possible solutions are contrasted with several requirements previously established, such as: required level of consensus, minimum number of opinions expressed, etc., with the aim of checking the consistency of these solutions.

In Tong and Bonissone (1980), a technique for LDM is presented which makes use of linguistic labels with fuzzy semantics in order to deal with the uncertainty inherent in this type of problem. Its authors also indicated that the results obtained by applying any model supporting the decision-making must be expressed in natural language.

Other authors, such as Kacprzyk and Zadrozny (2001) and Massanet et al. (2014), state that it does not seem appropriate to make decisions based on numerical information when a linguistic model close to the human cognitive model has been developed.

\subsection{2-tuple linguistic model}

The 2-tuple model was developed by Herrera and Martínez (2000) in order to improve the precision of the processes carried out in the CW. In this model, linguistic information is represented by means of two values (hence the name 2 -tuple), expressed as $\left(s_{i}, \alpha\right)$, where $s_{i}$ is a linguistic term and $\alpha$ is the symbolic translation of this term. The definitions of the main concepts defined by these authors are presented below:

Definition 2. (Symbolic translation): The symbolic translation of a linguistic term $s_{i} \in S=\left\{s_{0}, \ldots, s_{g}\right\}$ is a numerical value defined in $[-0.5,0.5)$, which represents the "difference of information" between an amount of information $\beta \in[0, g]$ obtained from a symbolic operation and the index of the closest linguistic term.

In this linguistic model, a series of functions are defined to carry out transformations between numerical values and those represented by 2 -tuples. 
Definition 3. (2-tuple representation): Let $S=\left\{s_{0}, \ldots, s_{g}\right\}$ be a set of linguistic terms and $\beta \in[0, g]$ the value obtained by the symbolic translation operation, then the 2 -tupla expresses the equivalent information to $\beta$ which is obtained by the following function:

$$
\begin{aligned}
& \Delta:[0, g] \rightarrow S \times[-0.5,0.5), \\
& \Delta(\beta)=\left(s_{i}, \alpha\right), \text { with } \begin{cases}s_{i}, & i=\operatorname{round}(\beta) \\
\alpha=\beta-i, & \alpha \in[-0.5,0.5),\end{cases}
\end{aligned}
$$

where round $(\beta)$ is the usual operator which calculates the closest integer value to $\beta$. Besides, it should be noted that $\Delta$ is bijective, so that:

$$
\Delta^{-1} S \times[-0.5,0.5) \rightarrow[0, g]
$$

which is defined as:

$$
\Delta^{-1}\left(s_{i}, \alpha\right)=i+\alpha
$$

Thus, based on the previous functions, the conversion of a linguistic term into a 2-tupla consists in adding a value zero as its symbolic translation. This form of representation is associated with a computational model which lets us perform processes of CW without losing information (Herrera, Martínez 2001a; Herrera et al. 2009).

\subsection{Linguistic aggregation process}

Below, and following Herrera and Martínez (2001b), a couple of aggregation operators for linguistic 2-tuples are defined. These operators will be used in this study to calculate the mean values of the opinions obtained from users (extended arithmetical mean operator) and the opinions expressed by experts (extended weighted mean operator).

Definition 4. (Extended arithmetical mean): Let $A=\left\{\left(r_{1}, \alpha_{1}\right), \ldots,\left(r_{n}, \alpha_{n}\right)\right\}$ be a set of linguistic 2 -tuples, its arithmetical average is calculated by applying the extended arithmetical mean operator, $\bar{x}^{e}$, defined as:

$$
\bar{x}^{e}\left(\left(r_{1}, \alpha_{1}\right), \ldots,\left(r_{n}, \alpha_{n}\right)\right)=\Delta\left(\frac{1}{n} \sum_{i=1}^{n} \Delta^{-1}\left(r_{i}, \alpha_{i}\right)\right)=\Delta\left(\frac{1}{n} \sum_{i=1}^{n} \beta_{i}\right) .
$$

Definition 5. (Extended weighted mean): Let $A=\left\{\left(r_{1}, \alpha_{1}\right), \ldots\left(r_{n}, \alpha_{n}\right)\right\}$ be a set of linguistic 2-tuples and $W=\left\{\left(w_{1}, \alpha_{1}\right), \ldots,\left(w_{n}, \alpha_{n}\right)\right\}$ a vector of 2 -tuples corresponding to the weights associated to each 2 -tupla of $A$. The extended weighted mean operator, $\bar{x}_{l}^{e}$, is defined as:

$$
\bar{x}_{l}^{e}=\Delta\left(\frac{\sum_{i=1}^{n} \Delta^{-1}\left(r_{i}, \alpha_{i}\right) \times \Delta^{-1}\left(w_{i}, \alpha_{i}\right)}{\sum_{i=1}^{n} \Delta^{-1}\left(w_{i}, \alpha_{i}\right)}\right) \text {. }
$$




\subsection{Calculating the level of consensus}

Several works have focused on determining the degree of consensus on linguistic models for decision-making (Alonso et al. 2013; Cabrerizo et al. 2010, 2015; Su et al. 2013; Morente-Molinera et al. 2015). In our case, the methodology to do this is based on the degree of coincidence of the answers given by the experts. The level of consensus $\left(C_{f}\right)$ among the $m$ experts participating in the decision-making process is carried out through the use of a technique which groups the same assessments made by such experts for each one of the alternatives $A_{i}$, i.e. the consensus for each alternative $C_{A_{i}}$, according to the following formula:

$$
C_{A_{i}}=\frac{\sum_{i=1}^{m}\left(v_{i} \times k_{i}\right)}{m},
$$

with:

where:

$$
C_{f}=\Delta\left(\frac{1}{n} \sum_{i=1}^{n} C_{A_{i}}\right)
$$

- $v_{i}$ represents the number of coinciding assessments of the $m$ experts, ordered from higher to lower, so that for each alternative $\sum v_{i}=m$,

- $k_{i}$ represents the multiplicative coefficient according to the posion of grouping of the assessments, this is, $k_{i}=(m-i) /(m-1)$,

- $m$ is the total number of experts,

$-n$ is the number of alternatives.

The value obtained is also represented as a 2-tuple.

\section{Hybrid Model for Decision-Making}

In this section, we present our Hybrid Model for Decision-Making (HMDM), which is proposed to evaluate and analyse a given problem in a business context and to obtain the best solution for it. A functional diagram of the model is presented in Figure 3. In it, two parts may be observed (left and right), which respectively correspond to each of the two stages in which the model is divided: Intelligent Information System (IIS) and Group Decision-Making Process. Both stages are explained in detail below, in the corresponding subsections.

\subsection{Intelligent Information System}

The IIS is made up of interconnected databases. The data stored in these databases are categorized by topics related to the organization's main areas of interest (hiring, quality of service, billing, legal issues, human resources, etc.). We denote these categories as $\mathcal{D}=\left\{d_{1}, \ldots, d_{h}\right\}$. Each category $d_{i}(\forall i \in\{1, \ldots, h\})$ is divided into more specific groups $B^{i}=\left\{b_{1}^{i}, \ldots, b_{q}^{i}\right\}$, where other data related to the main topic are stored. For example, in the case of service quality, specific topics may include satisfaction with the service, complaints, suggestions, etc. 


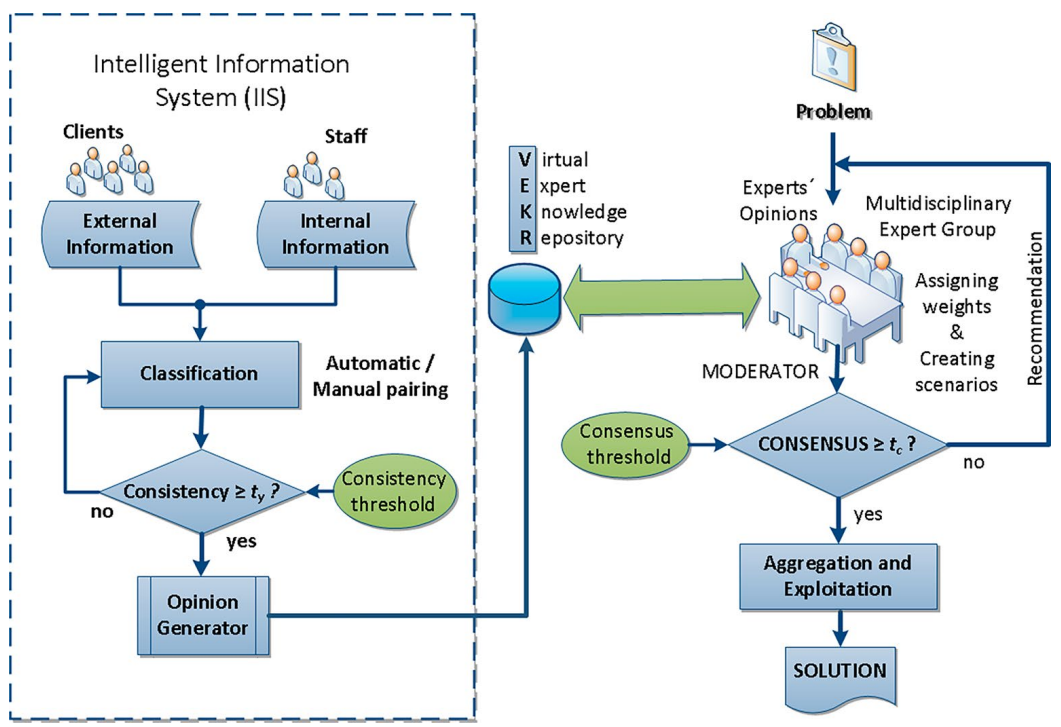

Fig. 3. Operating scheme of the Hybrid Model for Decision-Making

The objective of this module (IIS) is to process, classify and group the set of responses $R=\left\{\left(r_{1}, 0\right), \ldots,\left(r_{z}, 0\right)\right\}$, obtained for questions formulated using different media (personal, online and/or telephone surveys, social networks, websites, automatic data collection systems, etc.). These responses are given by the organization's external users (clients), $u^{c}=\left\{u_{1}^{c}, \ldots, u_{n}^{c}\right\}$, and internal users (staff), $u^{s}=\left\{u_{1}^{s}, \ldots, u_{m}^{s}\right\}$, using the set of linguistic labels that will later be converted to the 2-tuple linguistic model, following the format $\left(s_{i}\right.$, $\alpha$ ), with $\alpha=0$.

The classification of data inputted in the IIS includes pairing similar questions made at different times in different media and different surveys. This procedure can be conducted manually (by the staff in charge of data processing) or automatically (by specialized software). Afterwards, it is necessary to conduct a quality assessment process called data consistency calculation. The objective of this procedure is to verify that the subproduct obtained from the data pairing complies with the established quality requirements (greater or equal to the consistency threshold, $t_{y}$ ).

Consistency refers to the degree to which the different questions referring to the same topic are related to each other. This consistency indicates the degree to which the questions are in accordance with each other and, therefore, determines whether they can be paired to establish comprehensive opinions. A minimum threshold mechanism is generally used to resolve this issue by identifying the questions that score above this limit, which are considered to be consistent and can therefore be paired. A series of studies in the relevant literature use this type of mechanism (Alonso et al. 2008; Dong, Herrera-Viedma 2014). The model we propose employs this minimum threshold mechanism and the minimization operator described in Section 1.1, defined as $\min \left(s_{i}, s_{j}\right)=s_{i}$, if $s_{i} \leq s_{j}$. 
The total number of responses for each (non-paired) question or group of related (paired) questions, $p \in\{1, \ldots, k\}$, already classified according to the (external or internal) user profile, may be represented respectively as:

and

$$
R_{p}^{u^{c}}=\sum_{i=1}^{n} R_{p}^{u_{i}^{c}}
$$

$$
R_{p}^{u^{s}}=\sum_{j=1}^{m} R_{p}^{u_{j}^{s}} .
$$

It is necessary to aggregate these responses in order to create groups of opinions. This is done by using the extended arithmetical mean aggregation operator, defined in (4), in order to calculate the groups of external and internal client opinions, respectively, with the following equations:

and

$$
\bar{o}_{p}^{c}=\frac{1}{n} \sum_{i=1}^{n}\left(R_{p}^{u_{i}^{c}}, \alpha_{p}^{u_{i}^{c}}\right)
$$

$$
\bar{o}_{p}^{s}=\frac{1}{m} \sum_{j=1}^{m}\left(R_{p}^{u_{j}^{s}}, \alpha_{p}^{u_{j}^{s}}\right) .
$$

The collected responses and opinions obtained from the data aggregation process are expressed in the 2-tuple linguistic model $\left(s_{i}, \alpha_{i}\right)$, corresponding to the outputs from the first phase. These values (aggregate opinions) are stored in the corresponding specific topic group $b_{j}^{i} \in B^{i}$ of the Virtual Expert Knowledge Repository (VEKR), which will be consulted by experts in the second stage, which is explained in the following subsection.

\subsection{Group decision-making process}

Two groups of human experts intervene in this part of the process: $E_{a}=\left\{e_{a_{1}}, \ldots, e_{a_{q}}\right\}$, who are the experts that assign weights $\left(W=\left\{w_{1}, \ldots, w_{n}\right\}\right)$ to the set of proposed solution alternatives $A=\left\{A_{1}, \ldots, A_{n}\right\}$, and $E_{b}=\left\{e_{b_{1}}, \ldots, e_{b_{r}}\right\}$, who are the experts that evaluate such alternatives. Both groups do not necessarily have to include the same people, and it therefore is possible that $E_{a}=E_{b}$ or $E_{a} \neq E_{b}$, in which case (the latter) these sets may be disjoint or share some of the experts.

A critical part of this process is assessing the degree of consensus reached by the experts in terms of evaluating the solution alternatives. The degree of consensus is compared to the minimum consensus threshold initially established by the corresponding administrative hierarchical authority (consensus threshold, $t_{c}$ ). Formulas (6) and (7) are used in this case. A multiplicative linguistic coefficient $\left(k_{i}\right)$ refers to the value assigned to each label in the set $S=\left\{s_{0}, \ldots, s_{g}\right\}$. This coefficient is ordered according to the labels' degree of relevance (from the most to the least significant). There is also a variable $v_{i}$, which accounts for the number of times a label is repeated in the evaluation of an alternative $A_{i}$ (formerly grouped from the greatest to the least number of coincidences), with $\sum v_{i}=\left|E_{b}\right|+\left|e_{v}^{c}\right|+\left|e_{v}^{s}\right|=\left|E_{b}\right|+2=m$, where $m$ is the total number of experts who value the alternatives ( $E_{b}$ represents the group of human experts, while $e_{v}^{c}$ and $e_{v}^{s}$ are virtual experts, where the former corresponds to the aggregate opinion of external clients and the latter to internal clients). 
Therefore, the experts' final assessments of the proposed solution alternatives are expressed in the matrix $O_{i j}$, which consists of $n$ alternatives to be evaluated and $m$ (human and virtual) experts conducting the evaluation.

The consensus among the different experts for each alternative $A_{i}\left(C_{A_{i}}\right)$ is calculated by applying formula (6), while the final degree of consensus $\left(C_{f}\right)$ for the entire set of alternatives is obtained by aggregating the consensus reached for each individual alternative $A_{i}$, using formula (7).

If the established consensus requirement is fulfilled $\left(\geq t_{c}\right)$, the aggregation and exploitation phase follows. If the requirement is not met, the experts must continue to debate the evaluations until a sufficient degree of consensus has been reached (greater or equal to the established threshold), following the previous recommendations made by the subject serving as moderator.

Using the weights initially assigned by experts in $E_{a}$ and the assessments of human experts $\left(E_{b}\right)$ and virtual experts $\left(e_{v}^{c}\right.$ and $\left.e_{v}^{s}\right)$, the weighted aggregation considered for each alternative in the matrix $O_{i j}$ is calculated by applying the formula described in (5), which corresponds to the extended weighted mean aggregation operator considered. The application of said formula to the proposed model would be as follows:

$$
\bar{x}_{A_{i}}=\frac{\sum_{j=1}^{m} O_{i j} \times \bar{w}_{i}}{\sum_{j=1}^{m} w_{i j}}=L_{i},
$$

where $\bar{w}_{i}$ represents the arithmetical average of the expressed weights $w_{i j}$ (in 2-tuples) by experts in $E_{a}$ for each alternative $A_{i}$, and $L_{i}$ is the weighted aggregation of the assessments received for the corresponding alternative.

The final exploitation phase of this process consists of ordering the results obtained for each alternative $\left(L_{i}\right)$, in order from the most to the least significant label. The first option in the resulting ordered list will therefore be the solution that should be applied.

The proposed model can be better understood in the application example explained in next section.

\section{Application example}

For this example, we take the case of a company that is a telecommunication service operator. The problem to be discussed is the improvement in the customer service timetable. It is important to point out here that, in the last months, the company has been quietly investigating client expectations in relation to this problem. Below are some of the questions users were asked at different times and in different circumstances. The answers to these questions have been expressed according to a scale of five linguistic labels, which are $s_{0}=$ Strongly Disagree (SD), $s_{1}=$ Disagree (D), $s_{2}=$ Neutral $(\mathrm{N}), s_{3}=$ Agree $(\mathrm{A})$ and $s_{4}=$ Strongly Agree (SA).

- Which of the following alternatives would contribute to better customer service?

- From the following alternatives to improve customer service, which do you think is the most effective? 
- Indicate your level of agreement in relation to the following alternatives in customer service.

- How would you rate the following proposals of improvement in customer service?

- How would you assess the following alternatives for a better customer service?

The responses obtained are fed into the repository called VEKR (see Fig. 3), which stores the users' opinions about several topics of interest for the company.

In addition, a multidisciplinary team is created, which is made up of one or more experts from each of the areas involved. In this specific case, the team has one expert from the commercial area, another from the systems area, and one from the technical area (labelled as $e_{c}, e_{s}$ and $e_{t}$ respectively), who pre-evaluate the existing proposals and express their initial preferences for each alternative under consideration $\left(A_{1}, \ldots, A_{5}\right)$. With this procedure, it is possible to establish levels of importance (weights) for each alternative from the perspective of each area involved. This information, shown in Table 1, is used in the later stages of the process.

The alternatives under consideration are:

- $A_{1}$. Moving the current customer service timetable;

$-A_{2}$. Increasing the timeslot assigned to customer service;

$-A_{3}$. Changing the nature of customer service (face-to-face vs. phone or online);

- $A_{4}$. Forming alliances with entities with a different/wider customer service timetable;

- $A_{5}$. Opening new points of customer service.

Experts who carry out the previous assessment $\left(e_{c}, e_{s}\right.$ and $\left.e_{t}\right)$, in order to assign levels of importance (weights) to the different alternatives, are not necessarily in charge of the assessment of the alternatives which arise in the proposal of a solution. For this reason, those who participate in the latter stage are labelled as $e_{1}, e_{2}$ and $e_{3}$ (i.e., using different labels).

Table 1 . Weights initially assigned by experts to each alternative

\begin{tabular}{ccccc}
\hline & $e_{c}$ & $e_{s}$ & $e_{t}$ & Weighted Average \\
\hline$A_{1}$ & $\mathrm{~A}$ & $\mathrm{~A}$ & $\mathrm{SA}$ & $(\mathrm{A},+0.0833)$ \\
\hline$A_{2}$ & $\mathrm{SA}$ & $\mathrm{A}$ & $\mathrm{A}$ & $(\mathrm{A},-0.0833)$ \\
\hline$A_{3}$ & $\mathrm{~A}$ & $\mathrm{~N}$ & $\mathrm{~N}$ & $(\mathrm{~N},+0.0833)$ \\
\hline$A_{4}$ & $\mathrm{D}$ & $\mathrm{D}$ & $\mathrm{D}$ & $(\mathrm{D},+0.0000)$ \\
\hline$A_{5}$ & $\mathrm{SD}$ & $\mathrm{D}$ & $\mathrm{SD}$ & $(\mathrm{SD},+0.0833)$ \\
\hline
\end{tabular}

\section{Result analysis and discussion}

After making the appropriate queries to the VEKR repository, 1048 responses were found from external customers and 82 from internal customers in relation to this point of interest (in total 1130 users provided opinions on the case under study). Once these answers were aggregated using the aggregation operator presented in Definition 4, the resulting information was included in the columns labelled as $u^{c}$ and $u^{s}$ in Table 2, which respectively represent external customer opinions and internal customer (staff) opinions. 
Table 2. Assessments expressed by all the experts considered

\begin{tabular}{cccccc}
\hline & $e_{1}$ & $e_{2}$ & $e_{3}$ & $u^{c}(1048$ users $)$ & $u^{s}(82$ users $)$ \\
\hline$A_{1}$ & $\mathrm{~A}$ & $\mathrm{~A}$ & $\mathrm{~A}$ & $(\mathrm{~A},-0.0742)$ & $(\mathrm{A},-0.0756)$ \\
\hline$A_{2}$ & $\mathrm{SA}$ & $\mathrm{SA}$ & $\mathrm{A}$ & $(\mathrm{A},+0.0785)$ & $(\mathrm{A},+0.0764)$ \\
\hline$A_{3}$ & $\mathrm{~A}$ & $\mathrm{SA}$ & $\mathrm{SA}$ & $(\mathrm{A},+0.0759)$ & $(\mathrm{A},+0.0743)$ \\
\hline$A_{4}$ & $\mathrm{~N}$ & $\mathrm{~N}$ & $\mathrm{~A}$ & $(\mathrm{~N},+0.0256)$ & $(\mathrm{N},+0.0245)$ \\
\hline$A_{5}$ & $\mathrm{~N}$ & $\mathrm{D}$ & $\mathrm{N}$ & $(\mathrm{N},-0.1246)$ & $(\mathrm{D},+0.1247)$ \\
\hline
\end{tabular}

Initially, the information stored in the VEKR $\left(u^{c}\right.$ and $\left.u^{s}\right)$ could be considered as the opinion of only one additional expert. However, in this particular case, we decided to show the information coming from two independent experts, in order to observe the possible differences of opinion between both (external and internal) customer types.

Consequently, in the second stage, five experts are involved (as shown in Table 2); three of them are human experts $\left(e_{1}, e_{2}\right.$ and $\left.e_{3}\right)$ who assessed each alternative. In addition to these assessments, two vectors of preference provided by the IIS were added, which correspond to the aggregated assessments of the experts $u^{c}$ (external customers) and $u^{s}$ (internal customers).

As the minimum level of agreement among the experts required by the company was higher than label "A", it was necessary to calculate the consensus attained. In order to complete this calculation, we used the equations (6) and (7) provided in Subsection 1.5, the results of which are shown in Table 3.

Table 3. Degree of consensus reached by experts

\begin{tabular}{cc}
\hline Alternative & Degree of consensus \\
\hline$A_{1}$ & $(\mathrm{SA},-0.0000)$ \\
\hline$A_{2}$ & $(\mathrm{SA},-0.1000)$ \\
\hline$A_{3}$ & $(\mathrm{SA},-0.1000)$ \\
\hline$A_{4}$ & $(\mathrm{SA},-0.0500)$ \\
\hline$A_{5}$ & $(\mathrm{SA},-0.1000)$ \\
\hline Final Consensus & $(\mathrm{SA},-0.0700)$ \\
\hline
\end{tabular}

For calculations on the level of consensus among the five experts involved $\left(e_{1}, e_{2}, e_{3}, u^{c}\right.$, $u^{s}$ ), five levels of grouping were chosen, since we were working with five possible answers or linguistic labels (i.e., $|T(V)|=5$ ). As can be observed in Table 2, which collects the assessments given by all the experts, $v_{1}=5$ for the alternative $A_{1}$, since the five assessments correspond to the same label ("A"). So, $\forall j=2, \ldots, 5, v_{j}=0$. For $A_{2}, v_{1}=3$ (there are 3 "A" labels) and $v_{2}=2$ (there are 2 "SA" labels). The same calculation procedure was applied to the rest of the alternatives. In this example, the multiplicative coefficients for any alternative are $k_{1}=1, k_{2}=0.75, k_{3}=0.5, k_{4}=0.25$ and $k_{5}=0$.

Scores at levels equal to or higher than $v_{3}$ would indicate low levels of consensus and would require the intervention of the expert who plays the role of moderator and who would, in this case, activate the Recommendation process (see Fig. 3). 
The final degree of consensus (see Final consensus row in Table 3) is calculated as the average of the degrees of consensus attained by all the experts for each alternative considered, and is expressed in the 2-tuple linguistic model. The total average is (SA,-0.0700), which fulfils the minimum score ("A" = "Agree") required by the board of directors of the company for this specific decision-making process.

Using the model shown in Figure 3 and the different definitions presented in Section 1, we obtain the results which are expressed in Table 4 . Figure 4 provides a graphical semantic representation of the results obtained from the application of our model (HMDM) to this case study. These results are also expressed in the 2-tuple linguistic model.

Table 4. Results sorted according to their importance (expressed in linguistic 2-tuples)

\begin{tabular}{cc}
\hline Alternative & Importance \\
\hline$A_{2}$ & $(\mathrm{~A},+0.0576)$ \\
\hline$A_{1}$ & $(\mathrm{~N},+0.1000)$ \\
\hline$A_{3}$ & $(\mathrm{~N},+0.0134)$ \\
\hline$A_{4}$ & $(\mathrm{D},-0.1100)$ \\
\hline$A_{5}$ & $(\mathrm{SD},+0.0333)$ \\
\hline
\end{tabular}

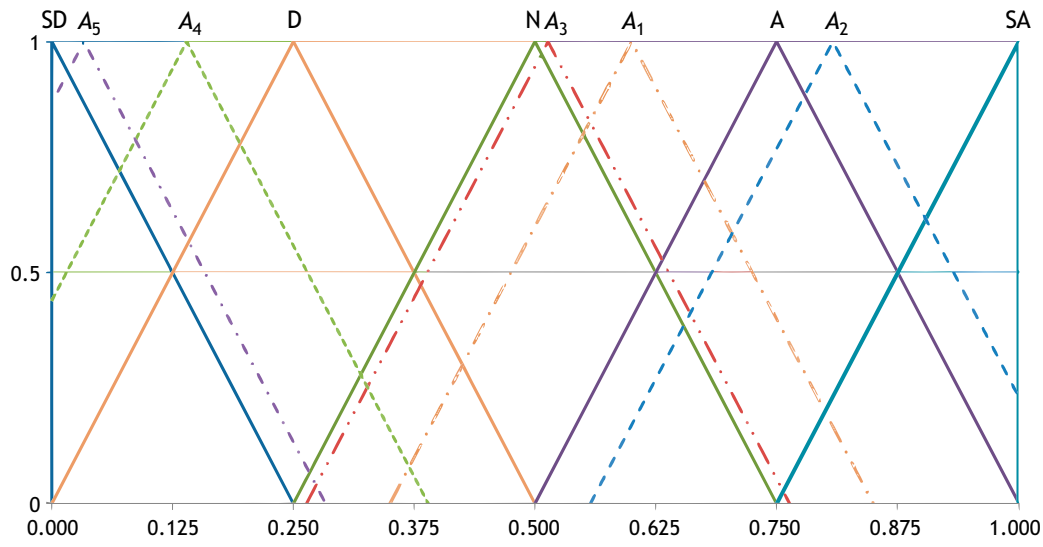

Fig. 4. Graphical result obtained by applying our HMDM

From the analysis carried out, we obtain an ordered list of the alternative solutions to the problem addressed (see Table 4), going from the ones which have a higher degree of membership $(\mathrm{A},+0.0567)$ to those which have a lower degree of membership $(\mathrm{SD},+0.0333)$. This can also be expressed as $A_{2}>A_{1}>A_{3}>A_{4}>A_{5}$. Here, we can observe that the best solution to the problem in question corresponds to alternative $A_{2}$ (which can also be observed in Fig. 4). In other words, the alternative of "Increasing the timeslot assigned to customer service" is the best solution. 


\section{Conclusions and future work}

We have presented a hybrid decision-making model which combines the automatic processing of opinions provided by customers or users of a given service (first stage of the model) along with the appraisals of a group of experts in the area (second stage of the model). To use this model, experts had to consult the aggregated opinions calculated in the first stage and reach at least a pre-established minimum level of consensus in order to obtain the solution to the problem which was initially presented.

This decision-making model has been specially designed to be applied in the ICT sector. Thus, we aim to contribute to problem-solving in real decision-making cases in one of the sectors which has a high level of impact on the economy of a country. Another important objective pursued by the model is to help ensure that the decisions made on a daily basis take into account the opinions of those who use the services of the businesses involved in this sector.

To validate the model presented, it has been applied to a specific example of decision-making in a telecommunication company in relation to a problem in its commercial area that was affecting the company's image. In this article, we have described how it was employed and we have analysed the results obtained. This model could be applied in a similar way to many other decision-making problems in the ICT sector, or, even, in other sectors.

With the development of this work, we have attempted to mitigate the effects of the limitations involved when using experts in decision-making. Thus, the proposed method presents the following advantages:

- There is increased democracy in decision-making in relation to key problems and issues that companies must address, which, in turn, results in more coherent solutions.

- It is not necessary to transform the opinions received (in natural language) into numbers, which would result in a loss of information, as occurs with any translation process. This advantage is due to the application of the computing with words, using a methodology based on fuzzy logic and supported by the 2-tuple linguistic model. This allows us to work directly with information provided in natural language without information loss.

- It involves a computerized process, which avoids manipulation of information. This entails managing the answers provided to different questions by the costumers. These answers make up the opinions which are stored in an aggregated way in a repository, having been automatically processed (by the IIS). This mechanism facilitates the management of the answers and avoids skewed interpretations which could influence the final solution.

- It allows for geographical delocalisation, which means that the experts do not have to meet in the same place, since it is possible to carry out the process online. In practice, then, the use of experts may be fairly extensive (global scale) and varied (multidisciplinary), and this enriches the decision-making process.

- Despite being a computerized system, decision-making responsibilities are not diluted, which is sometimes a problem for organisations. In our model, the processes 
and opinions provided by each expert are registered at all times, which means that it is possible to know the responses given by each participant in relation to the question posed.

- The process is fast and the results are obtained immediately. This has positive repercussions on savings of both financial and opportunity costs arising from delayed decision-making.

From the analysis carried out and the experience gained in the process, it is possible to conclude that the proposed model has the potential to contribute in a positive way to decision-making in companies or organisations who decide to use it. The plurality of opinions obtained from both internal and external sources enriches the information that is available to the expert group and offers different perspectives in relation to a given problem.

Additionally, the use of a methodology which is based on fuzzy logic involves a better modelling of problems expressed in qualitative terms. In the example provided, the opinions are expressed using linguistic criteria. This allows us to more faithfully represent the opinions collected, which, in turn, means no loss of information, since opinions expressed in natural language are directly processed without the need to transform such qualitative information into numerical values.

As an extension of this investigation, we have planned to apply our hybrid decision-making model to other areas which are connected to the ICT sector, such as the ones corresponding to the developers of software (mobile apps, computer programs, etc.) and manufacturers of hardware (smartphones, tablets, laptops, TVs, etc.), among others. In addition, since the IIS of our model is modular, we intend to enhance its analytical capacity by refining its modules and/or adding new modules in order to provide a model with greater levels of robustness and flexibility. Moreover, other interesting future line to explore would be the ontological approach to support CW-based systems (Reformat, Ly 2009), in order to enrich aspects related to analysis of opinions expressed in natural language to extract semantic annotations to be used in CW (De Maio et al. 2014), and even to use (fuzzy) ontologies to support decision-making through description logic reasoning (De Maio et al. 2012).

\section{Acknowledgements}

The authors would like to acknowledge the financial support received from European Regional Development Funds (FEDER) for the Research Projects TIN2012-38600 and TIN2013-40658-P, as well as the financial support received from the Andalusian Government for the Excellence Project TIC-5991.

\section{References}

Alonso, S.; Chiclana, F.; Herrera, F.; Herrera-Viedma, E.; Alcalá-Fdez, J.; Porcel, C. 2008. A consistency based procedure to estimate missing pairwise preference values, International Journal of Intelligent Systems 23(2): 155-175. http://dx.doi.org/10.1002/int.20262

Alonso, S.; Pérez, I. J.; Cabrerizo, F. J.; Herrera-Viedma, E. 2013. A linguistic consensus model for web 2.0 communities, Applied Soft Computing 13(1): 149-157. http://dx.doi.org/10.1016/j.asoc.2012.08.009 
Bonissone, P. P. 1980. A fuzzy sets based linguistic approach: theory and applications, in Proceedings of the 12th Conference on Winter Simulation, 3-5 December 1980, Orlando Marriott, Orlando, FL. IEEE Press, 99-111.

Cabrerizo, F. J.; Alonso, S.; Herrera-Viedma, E. 2009. A consensus model for group decision making problems with unbalanced fuzzy linguistic information, International Journal of Information Technology \& Decision Making 8(01): 109-131. http://dx.doi.org/10.1142/S0219622009003296

Cabrerizo, F. J.; Moreno, J. M.; Pérez, I. J.; Herrera-Viedma, E. 2010. Analyzing consensus approaches in fuzzy group decision making: advantages and drawbacks, Soft Computing 14(5): 451-463. http://dx.doi.org/10.1007/s00500-009-0453-x

Cabrerizo, F. J.; Al-hmouz, R.; Morfeq, A.; Balamash, A. S.; Herrera-Viedma, E. 2015. Fuzzy decision making and consensus: challenges, Journal of Intelligent \& Fuzzy Systems. To appear.

Carrasco, R. A.; Villar, P.; Hornos, M. J.; Herrera-Viedma, E. 2011. A linguistic multi-criteria decision making model applied to the integration of education questionnaires, International Journal of Computational Intelligence Systems 4(5): 946-959. http://dx.doi.org/10.1080/18756891.2011.9727844

Carrasco, R. A.; Villar, P.; Hornos, M. J.; Herrera-Viedma, E. 2012. A linguistic multicriteria decisionmaking model applied to hotel service quality evaluation from web data sources, International Journal of Intelligent Systems 27(7): 704-731. http://dx.doi.org/10.1002/int.21546

De Maio, C.; Fenza, G.; Furno, D.; Loia, V.; Senatore, S. 2012. OWL-FC: an upper ontology for semantic modeling of Fuzzy Control, Soft Computing 16(7): 1153-1164. http://dx.doi.org/10.1007/s00500-011-0790-4

De Maio, C.; Fenza, G.; Gallo, M.; Loia, V.; Senatore, S. 2014. Formal and relational concept analysis for fuzzy-based automatic semantic annotation, Applied Intelligence 40(1): 154-177. http://dx.doi.org/10.1007/s10489-013-0451-7

Dong, Y.; Herrera-Viedma, E. 2014. Consistency-driven automatic methodology to set interval numerical scales of 2-tuple linguistic term sets and its use in the linguistic GDM with preference relation, IEEE Transactions on Cybernetics 99: 1-13.

Elbarkouky, M. G.; Ezeldin, A. S.; El-Assaly, A. 2012. A multi-criteria decision-making (MCDM) framework for prioritizing damaged infrastructure and services facilities in Egypt using sustainability objectives, in Annual Conference of the Canadian Society for Civil Engineering: Leadership in Sustainable Infrastructure, 6-9 June 2012, Edmonton, Canada.

Gal, T.; Stewart, T. J.; Hanne, T. 1999. Multi criteria decision making: advances in MCDM models, algorithms, theory, and applications. Boston: Kluwer Academic Publishers.

Herrera, F.; Alonso, S.; Chiclana, F.; Herrera-Viedma, E. 2009. Computing with words in decision making: foundations, trends and prospects, Fuzzy Optimization and Decision Making 8(4): 337-364. http://dx.doi.org/10.1007/s10700-009-9065-2

Herrera, F.; Martínez, L. 2000. A 2-tuple fuzzy linguistic representation model for computing with words, IEEE Transactions on Fuzzy Systems 8(6): 746-752. http://dx.doi.org/10.1109/91.890332

Herrera, F.; Martínez, L. 2001a. The 2-tuple linguistic computational model: advantages of its linguistic description, accuracy and consistency, International Journal of Uncertainty, Fuzziness and Knowledge-Based Systems 9: 33-48. http://dx.doi.org/10.1142/S0218488501000971

Herrera, F.; Martínez, L. 2001b. A model based on linguistic 2-tuples for dealing with multigranular hierarchical linguistic contexts in multi-expert decision-making, IEEE Transactions on Systems, Man, and Cybernetics, Part B: Cybernetics 31(2): 227-234. http://dx.doi.org/10.1109/3477.915345

Hu, S. K.; Lu, M. T.; Tzeng, G. H. 2014. Exploring smart phone improvements based on a hybrid MCDM model, Expert Systems with Applications 41(9): 4401-4413. http://dx.doi.org/10.1016/j.eswa.2013.12.052

Kabak, M.; Dağdeviren, M. 2014. A hybrid MCDM approach to assess the sustainability of students' preferences for university selection, Technological and Economic Development of Economy 20(3): 391-418. http://dx.doi.org/10.3846/20294913.2014.883340 
Kacprzyk, J.; Zadrozny, S. A. 2001. Computing with words in decision making through individual and collective linguistic choice rules, International Journal of Uncertainty, Fuzziness and KnowledgeBased Systems 9(supp01): 89-102. http://dx.doi.org/10.1142/S0218488501001010

Katz, R. L. 2009. El papel de las TIC en el desarrollo. Propuesta de América Latina a los retos económicos actuales. Colección Fundación Telefónica. Barcelona: Ariel.

Keršulienè, V.; Turskis, Z. 2011. Integrated fuzzy multiple criteria decision making model for architect selection, Technological and Economic Development of Economy 17(4): 645-666. http://dx.doi.org/10.3846/20294913.2011.635718

Massanet, S.; Riera, J. V.; Torrens, J.; Herrera-Viedma, E. 2014. A new linguistic computational model based on discrete fuzzy numbers for computing with words, Information Sciences 258: 277-290. http://dx.doi.org/10.1016/j.ins.2013.06.055

Morente-Molinera, J. A.; Pérez, I. J.; Ureña, M. R.; Herrera-Viedma, E. 2015. On multi-granular fuzzy linguistic modeling in group decision making problems: a systematic review and future trends, Knowledge-Based Systems 74: 49-60. http://dx.doi.org/10.1016/j.knosys.2014.11.001

Naser, A; Concha, G. 2014. Rol de las TIC en la gestión pública y en la planificación para un desarrollo sostenible en América Latina y el Caribe. Serie Gestión Pública. CEPAL, Vol. 79. Santiago de Chile: United Nations Publications.

Oh, Y.; Suh, E. H.; Hong, J.; Hwang, H. 2009. A feasibility test model for new telecom service development using MCDM method: a case study of video telephone service in Korea, Expert Systems with Applications 36(3): 6375-6388. http://dx.doi.org/10.1016/j.eswa.2008.07.051

Park, J.; Jeong, H. Y. 2013. The QoS-based MCDM system for SaaS ERP applications with Social Network, Journal of Supercomputing 66(2): 614-632. http://dx.doi.org/10.1007/s11227-012-0832-4

Peres, W.; Hilbert, M. R. 2009. La Sociedad de la Información en América Latina y el Caribe: Desarrollo de las Tecnologías y Tecnologías para el Desarrollo. Serie Libros de la CEPAL, Vol. 98. Santiago de Chile: United Nations Publications.

Pérez, J. (Coord.) 2004. Productividad, crecimiento económico y TIC [online], [cited 13 May 2015]. 41 p. Available form Internet: http://www.usc.es/atpemes/IMG/pdf/04_03_30productividad_ crecimiento_TIC.pdf

Pérez, I. J.; Cabrerizo, F. J.; Herrera-Viedma, E. 2010. A mobile decision support system for dynamic group decision-making problems, IEEE Transactions on Systems, Man and Cybernetics, Part A: Systems and Humans 40(6): 1244-1256. http://dx.doi.org/10.1109/TSMCA.2010.2046732

Porcel, C.; Tejeda-Lorente, A.; Martínez, M. A.; Herrera-Viedma, E. 2012. A hybrid recommender system for the selective dissemination of research resources in a technology transfer office, Information Sciences 184(1): 1-19. http://dx.doi.org/10.1016/j.ins.2011.08.026

Reformat, M.; Ly, C. 2009. Ontological approach to development of computing with words based systems, International Journal of Approximate Reasoning 50(1): 72-91. http://dx.doi.org/10.1016/j.ijar.2008.03.004

Su, W.; Zeng, S.; Ye, X. 2013. Uncertain group decision-making with induced aggregation operators and Euclidean distance, Technological and Economic Development of Economy 19(3): 431-447. http://dx.doi.org/10.3846/20294913.2013.821686

Tong, R. M.; Bonissone, P. P. 1980. A linguistic approach to decision making with fuzzy sets, IEEE Transactions on Systems, Man and Cybernetics 10(11): 716-723. http://dx.doi.org/10.1109/TSMC.1980.4308391

Tseng, M. L. 2011. Using hybrid MCDM to evaluate the service quality expectation in linguistic preference, Applied Soft Computing Journal 11(8): 4551-4562. http://dx.doi.org/10.1016/j.asoc.2011.08.011

Zadeh, L. A. 1975. The concept of a linguistic variable and its application to approximate reasoning: Part III, Information Sciences 9(1): 43-80. http://dx.doi.org/10.1016/0020-0255(75)90017-1

Zavadskas, E. K.; Turskis, Z. 2011. Multiple criteria decision making (MCDM) methods in economics: an overview, Technological and Economic Development of Economy 17(2): 397-427.

http://dx.doi.org/10.3846/20294913.2011.593291 
Andrés CID-LÓPEZ got his Electronic Engineer title in the Specialty of Semiconductor Devices and Microelectronic (degree of Master of Science), in the Polytechnic Institute of Lvov (Ukraine, 1988). In 2002, he received his Master in Management of Telecommunication Enterprises, in the Polytechnical School of the Litoral (Ecuador, 2002). He has been linked for more than twenty years to the Telecommunication Business. Since 2012, he is a $\mathrm{PhD}$ candidate of the Official $\mathrm{PhD}$ Program on Information and Communication Technologies (ICT) at the Higher Technical School of Computer and Telecommunication Engineering, University of Granada (Spain). His main research interests are service quality and decision-making models in the ICT sector.

Miguel J. HORNOS is a senior lecturer at the University of Granada (Spain), where he previously received both an MSc in Computer Science and a $\mathrm{PhD}$ in Computing. His main fields of research are Multicriteria Decision-Making, Ubiquitous Computing and Intelligent Environments, Specification and Verification of Complex Software Systems, and Information and Communication Technologies (ICT) Applied to Business and Education, on which he has written several textbooks as well as around 90 research papers published in international journals and conferences specialized on these topics. He is currently involved in various (European, national, regional and local) Research, Development and Innovation (R\&D\&I) Projects. Dr Hornos is a member of the Editorial Board of the Journal of Reliable Intelligent Environments (published by Springer) and is also serving as reviewer for several international journals and conferences.

Ramón Alberto CARRASCO received his $\mathrm{PhD}$ degree in Computing from Granada University, Granada, Spain, in 2003. He currently leads the data mining lab applied to marketing and market Research at the Spanish bank BMN. His fields of research include NoSQL databases, data mining, data warehouse, sentiment analysis, business intelligence, decision making models and intelligent information systems applied to marketing, business, tourism and education, on which he has written several textbooks as well as around 50 research papers published in international journals and conferences specialized on these topics. He has been involved in various R\&D\&I projects and is serving as reviewer for several international journals and conferences. He is a member of the SCI2S Research Group. He has been an assistant Professor at the University of Granada (from 2004 to 2013) and at the Complutense University, Madrid, Spain (from 2013), where he teaches in the Master of Data Mining and Business Intelligence.

Enrique HERRERA-VIEDMA is Full Professor in Computer Science of the Dept. of Computer Science and A.I., University of Granada (Spain). He received his $\mathrm{PhD}$ in Computer Science from the University of Granada (Spain) in 1996, and from 1999 to 2015 he was Vice-dean of Research of the Library Science School, University of Granada. From July 2015 he is Vice-Chancellor of Research and Innovation in University of Granada. He has published more than 300 refereed journal and conference papers related with the areas of fuzzy decision making, computing with words, linguistic preference modelling, fuzzy information retrieval, recommender systems, Web quality, social media, digital libraries and bibliometrics. Dr. Herrera-Viedma is Associate Editor in IEEE Trans. on Systems Man and Cybernetics: Systems, Information Sciences, J. of Intelligent and Fuzzy Systems, Fuzzy Optimization and Decision Making, Knowledge Based Systems, Applied Soft Computing and Soft Computing. His H-index is 46 according to the WoS with more than 8000 citations and 64 according to Google Scholar with more than 16000 citations. He has recently published in Science [339:6126 (2013) p. 1382] on the new role of the public libraries, and in 2014 he was included in the List of Highly Cited Researchers in Engineering by Thomson Reuters. 